Article

\title{
In-Situ Fretting Wear Analysis of Electrical Connectors for Real System Applications
}

\author{
Arpith Siddaiah ${ }^{1}\left(\mathbb{D}\right.$, Ashish K. Kasar ${ }^{1}\left(\mathbb{D}\right.$, Vishal Khosla ${ }^{2}$ and Pradeep L. Menezes ${ }^{1, *(1)}$ \\ 1 Department of Mechanical Engineering, University of Nevada-Reno, Reno, NV 89557, USA; \\ asiddaiah@nevada.unr.edu (A.S.); akasar@nevada.unr.edu (A.K.K.) \\ 2 Rtec Instruments, San Jose, CA 95131, USA; vkhosla@rtec-instruments.com \\ * Correspondence: pmenezes@unr.edu
}

Received: 13 May 2019; Accepted: 12 June 2019; Published: 14 June 2019 updates

\begin{abstract}
The tribological behavior of electrical contacts, especially separable type electrical connectors at low contact loads, are considered. The reliability of these connectors has been a major concern due to the fretting phenomenon that can lead to an unacceptable increase in contact resistance. This study analyzes various aspects of the fretting mechanism from a tribological perspective where friction and wear are the primary cause of degradation in electrical components. With the use of precise tribological equipment (high data acquisition rate of $5000 \mathrm{~Hz}$ ), the electrical contact resistance and coefficient of friction at the contact interface are measured. The measurements were made in-situ for a simulated fretting environment under various constant loading conditions. It was observed that low contact loads $(1 \mathrm{~N})$ and low fretting frequency $(1 \mathrm{~Hz})$ leads to a high degree of fluctuation in the coefficient of friction. However, for the same conditions, the lowest wear rate and electrical contact resistance were observed. The reason behind this could be due to the lack of continuous electrical contact and a high degree of fretting frequency under low contact loads, ultimately leading to extended periods of an open circuit. Experimental analysis indicates the existence of an optimum loading condition at which the fretting wear effect is at its minimum. Detailed analysis of post fretting surface roughness, coating wear, and wear debris is conducted, as well as transfer film formations to explain the mechanism of fretting observed.
\end{abstract}

Keywords: friction; wear; fretting; electrical connector

\section{Introduction}

Electrical connectors are components that provide a separable connection between two elements of an electronic circuit, ideally without any signal distortion or power loss. The two critical functionalities of any connector are to have a separable connection and no/minimal signal or power loss. The understanding and development of both these critical functions depends heavily on application, environment, and design. A connector assembly typically includes a contact interface, contact finish, contact spring, and housing. The connector reliability has gained new importance as electronics, especially Internet of Things (IoTs), consumer electronics, computers, telecommunication equipment, etc. become essential both in personal and business life. Repeated insertion and withdrawal of a connector can cause wear and mechanical damage to the electrical contact surfaces, rendering those surfaces more susceptible to environmental degradation and failures. Connectors typically degrade by a combination of a few mechanisms-corrosion, wear, and reduction in contact force. The corrosion and wear mechanisms depend on the contact surfaces and their material properties, whereas the decrease in contact force depends on the spring material and design. Widely used materials such as copper and copper alloys are prone to corrosion and oxidation, while the connector quality can be increased drastically by using exotic materials, however expensive connectors do not always sell well enough to justify the cost. The present 
study investigates the tribological degradation of electrical connectors where the effect of fretting wear on the friction and electrical contact resistance is analyzed.

Fretting wear is one of the most common accelerated surface damages that occurs at the interface of contacting materials which are subjected to small oscillatory movement [1-3]. Hence, fretting is a widespread problem of practical importance that affects a wide range of electrical equipment, press fits, riveted and bolted joints, leaf springs, heat exchangers, and even nuclear fuel elements. One of the most economically important systems in which fretting can cause severe degradation is electrical components with separable contacts such as connectors, relays, switches, and bus bars. This is especially true for contacts that are mated at relatively low forces. Another major characteristic that influences fretting is the materials from which the contact surfaces are made. Based on many such factors, fretting uniquely affects electrical devices. Fretting wear may also be due to the worn-out coating layer which exposes the base metal, thereby forming wear debris and oxides. These materials further accumulate at the interface, forming a thick, highly localized insulating layer which increases the contact resistance progressively, eventually resulting in an open circuit. It is not fretting in itself that may fail an electrical circuit, but it certainly is one of the major contributing factors that will affect the electrical stability of a joint [3,4]. Understanding the effect of fretting in low voltage and low power applications is essential since this phenomenon is inherent in all contact involving noble and non-noble metal contacts. This is because fretting is a time-related process and results in failure due to the accumulation of wear and oxide debris over time.

Experiments have shown that micromotion of amplitudes in the order $10^{-7} \mathrm{~m}$ can easily produce fretting in electrical connectors [5-7]. Further, surface micro-slip makes it hard to find an upper limit that would define a safe working condition for the electrical connector. For consistent electrical contact, it is necessary to have a low and stable contact resistance. Hence, it is imperative to choose materials and/or coatings that have high electrical conductivity and nobility, which is to say that they should have the ability to resist the formation of insulating films, such as oxides, to maintain effective metallic contact. The importance of tribology in the investigation of any electrical contact was well elaborated upon by Saka et al. [8]. It was also the first research to convincingly show the role of wear debris in the reduction of electrical contacts. Studies on electrical connectors removed from service in distribution transformers were carried out by Braunovic [9]. It was found that the accumulated materials in the wear debris are due to delamination wear, severe abrasion, and transferred layers of the mating pair. A complex interactive mechanism was provided by the authors to explain different phases of fretting, which were responsible for the deterioration of the contact interface. Further, Kogut and Etsion [10] carried out mathematical studies on electrical conductivity and friction force behavior in compliant connectors. They found that the thermoelectric efficiency of the connectors described in terms of the slenderness ratio and loading parameters had minimal effect on electrical conductivity but were able to increase the friction force. It was reported that smoother surfaces had a higher friction force and electrical conductivity, with the same being observed at higher loads. But, softer surfaces resulted in a higher electrical conductivity with a reduced friction force. There have also been investigations concerning fretting in silver plated electrical contacts using a friction energy density approach by Perrinet et al. [11] and Laporte et al. [3]. These investigations provide a very valuable mathematical and experimental perspective of fretting, however there is still an assumption of consistent fretting frequency and idealized environmental conditions like humidity and temperature. Further investigations concerning the degradation of these coatings, especially for that of gold [12,13] and tin-plated connectors [14,15], have been conducted with similar assumptions for both dry and lubricated conditions. Some of these considerations also involve contact geometry as a cylinder on a fixed flat rigid surface, wherein the most common type of electrical contacts in practical use are cylinder on cylinder type.

Though there have been many such models proposed to explain fretting and fretting corrosion, including the classic models proposed by Heitz [16] and Hurricks [17], there is no one theory that has been able to incorporate all of its effects. This is mostly due to a large number of variables that are associated with fretting [18]. It is challenging to control and monitor all these parameters at the 
same time. Hence in most of the research concerning fretting, few of the parameters are assumed to be constant or idealized to be in a specific environment $[1,3,7]$. When considering an electrical/electronic contact, the most crucial factor to consider is the micro-displacements in normal and tangential direction under the fretting conditions. These micro-displacements are the primary cause for deformations and wear of the contacting surfaces, which leads to tribological problems [19]. This involves issues such as surface activation, corrosion, the formation of wear particles, and contamination on contact spots, which ultimately leads to a reduction in contact resistances, as shown in schematic Figure 1 [18]. The current study aims at analyzing the effect of fretting frequency and load on the formation of wear debris and examines the wear life of coated noble-metal. The study also aims at analyzing the wear track and mechanism of the wear observed.

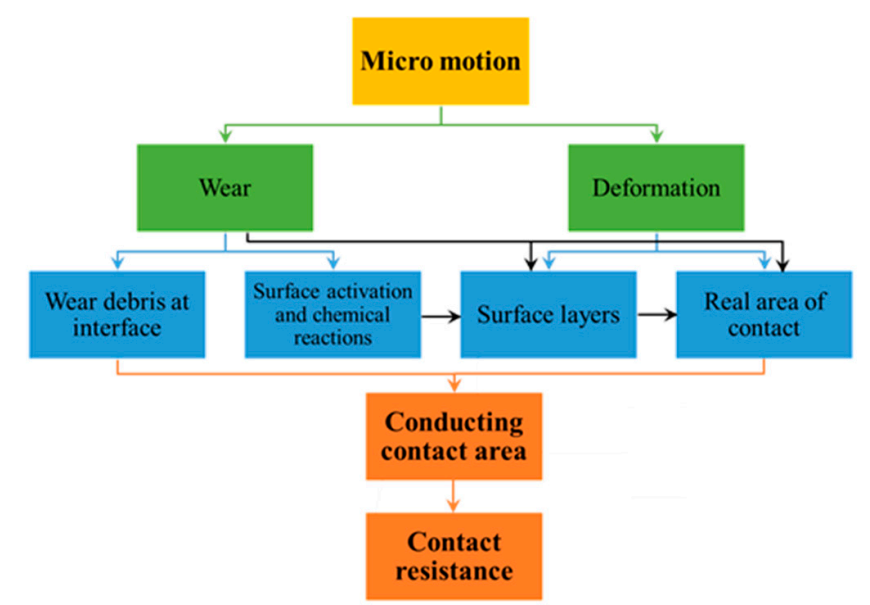

Figure 1. Influence of micro-motion causing tribological problems which affect contact resistance.

\section{Materials and Methods}

A unique test setup shown in Figure 2 allows real connectors to be mounted for testing. In this case, cylindrical contact is simulated using R-tec Multifunction Tribometer (MFT-5000, Rtec-instruments, San Jose, CA, USA). The set houses a dedicated fixture that is designed and built by R-tec Instruments to simulate fretting in a controlled measurable environment that is observed in most common electrical contacts. The oscillatory motion of the upper specimen holder was provided by a sensitive electromagnetic shaker. The lower specimen is fixed to a holder, which is linked to a piezoelectric load sensor to measure the evolution of tangential forces during the fretting cycles. The holders are electrically insulated from the rest of the machine to negate the effect of noise and grounding. The upper specimen holder had an accuracy of $0.1 \mu \mathrm{m}$ movement.

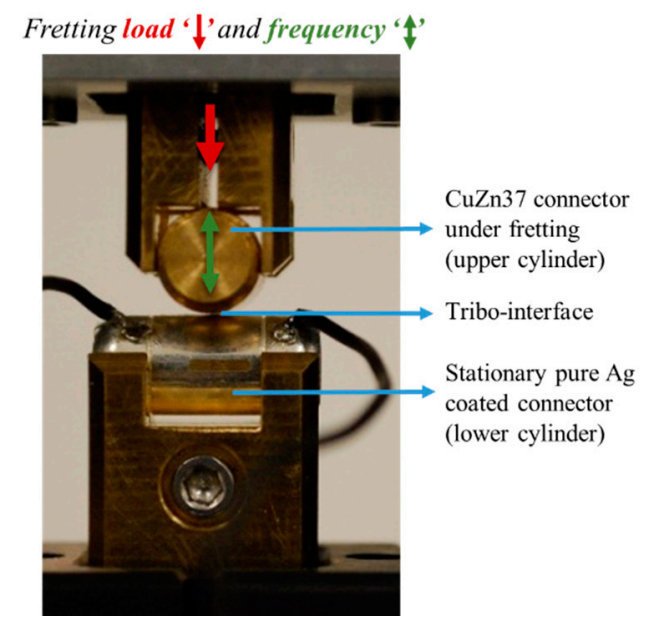

Figure 2. Test rig set-up to simulate the fretting phenomenon. 
As a consideration of practical application and working conditions for the connectors, a low voltage, low current condition was applied with normal load variation of $1-5 \mathrm{~N}$ and vibration frequency variations of 1-10 Hz. In-situ coefficient of friction, wear depth (nm resolution), electrical contact resistance (ECR) (micro-ohms), normal load $(\mathrm{N})$, tangential force amplitude $(\mathrm{mN})$, and sliding amplitude were recorded at a high data acquisition rate of $5000 \mathrm{~Hz}$ during the test (Figure 3). This accuracy in data acquisition is seen to play a very crucial role in mimicking real-life scenarios.

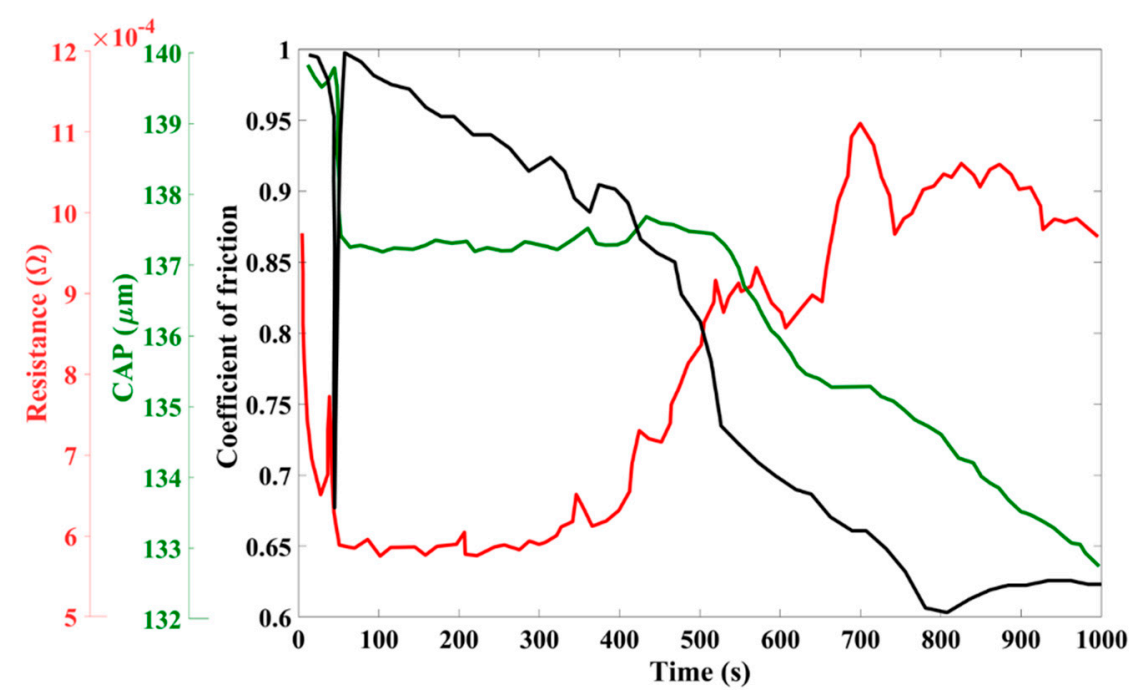

Figure 3. In-situ measurement of electrical contact resistance (ECR in $\Omega$ ), wear depth (in $\mu \mathrm{m}$ ), and coefficient of friction.

After the fretting wear test, the wear tracks and the connector surfaces were investigated using a Rtec 3D optical profilometer. The analysis of these 3D profiles yielded the wear depth $(\mu \mathrm{m})$ and various roughness parameters, which have been reported in the present study.

\subsection{Contact Conditions and Electrical Resistance Measurement}

The experiment allows for small and precise motions in forms of oscillating, linear, rotation axial, and/or lateral directions. The contacts were wired for four-wire resistance measurement, as shown in the schematic Figure 4.

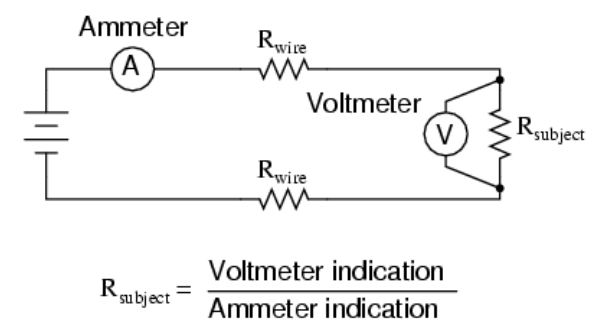

Figure 4. Schematic of four-wire resistance measurement.

The contact type being tested above can be considered not only to simulate the type of connector shape for the specimen in focus, but also can be related to various shapes of similar connectors as shown in Figure 5. All these connectors have similar contact interfaces and, hence, the versatility of these experiments is also to be noted. 


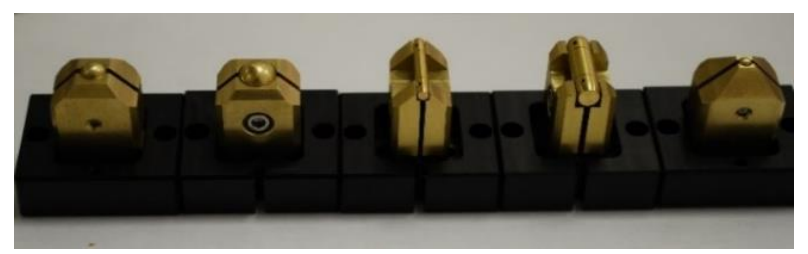

Figure 5. Various shapes of connectors that have similar contact interfaces.

A contact condition of equal diameter cylinders crossed with their axes at right angles is considered, as shown below in Figure 6 [20].

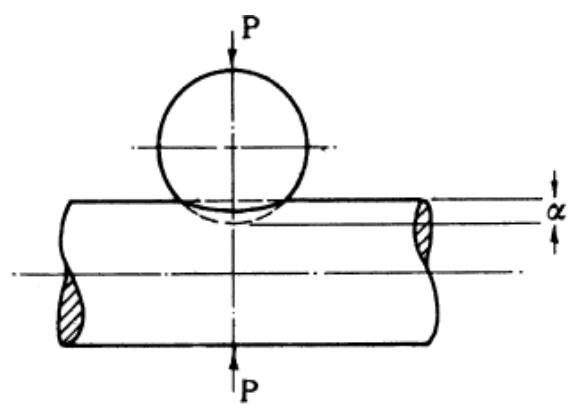

Figure 6. Perpendicular axes cylindrical contacts with equal diameters.

The total elastic compression for the above configuration is given by:

$$
\alpha=\frac{3 \pi^{2 / 3}}{2} \times P^{\frac{2}{3}} \times\left(\mathrm{V}_{1}+\mathrm{V}_{2}\right)^{2 / 3} \times(1 / D)^{1 / 3}
$$

where,

$\alpha$-the total elastic compression at the point or line of contact of two bodies, measured along the line of the applied force

$D$-Diameter of both cylindrical bodies $=9 \mathrm{~mm}$

$P$-Applied force $=$ normal load variation of $1-5 \mathrm{~N}$

E-Young's modulus of material of body

$\mathrm{E}_{1}=$ Young's modulus of upper cylinders $=110 \mathrm{Gpa}$

$\mathrm{E}_{2}=$ Young's modulus of lower cylinders $=76 \mathrm{Gpa}$

G-Modulus of rigidity of material of the body

$\mathrm{G}_{1}=$ modulus of rigidity s of upper cylinders $=40 \mathrm{Gpa}$

$\mathrm{G}_{2}=$ modulus of rigidity of lower cylinders $=27.8 \mathrm{Gpa}$

$\sigma$-Poisson's ratio $=\mathrm{E} /(2 \mathrm{G}-1)$

$\sigma_{1}=$ Poisson's ratio of upper cylinders $=0.3$

$\sigma_{2}=$ Poisson's ratio of lower cylinders $=0.37$

$\mathrm{V}_{1}$ (upper cylinder) $=\left(1-\sigma_{1}^{2}\right) / \pi \mathrm{E}_{1}$

$\mathrm{V}_{2}$ (lower cylinder) $=\left(1-\sigma_{2}^{2}\right) / \pi \mathrm{E}_{2}$

For the system of two cylindrical bodies in contact (with radii $D_{1} / 2$ and $D_{2} / 2$ ), as shown in Figure 6, the maximum Hertzian contact pressure and maximum shear stress can be calculated using the equations below:

The Hertzian half-width contact $b$ under applied normal load $P(1-5 \mathrm{~N})$ is given by the following equation:

$$
b=2 \sqrt{\frac{P D}{B V}}
$$


where $B$ is the length of the cylinders and $2 \pi / V=V_{1}+V_{1}$ is the equivalent reduced elastic modulus. Equivalent radius $D / 2$ is given by the following relation:

$$
\frac{2}{D}=\frac{2}{D_{1}}+\frac{2}{D_{2}}
$$

The mean and maximum pressures are given by:

$$
P_{\text {mean }}=\frac{P}{2 B b}, P_{\text {max }}=\frac{4 P_{\text {mean }}}{\pi}
$$

The maximum shear stress was calculated using the principal stresses $\left(\sigma_{x}, \sigma_{y}, \sigma_{z}\right)$ for cylindrical as below:

$$
\begin{aligned}
\tau_{x z} & =\frac{\sigma_{x}-\sigma_{z}}{2} \\
\tau_{y z} & =\frac{\sigma_{y}-\sigma_{z}}{2} .
\end{aligned}
$$

The maximum Hertzian contact pressure at the interface of the two bodies was found to be 791.6 MPa and a theoretical contact area of the interface was found to be $9.5 \times 10^{-3} \mathrm{~mm}^{2}$. The maximum shear stress at the interface was $245.4 \mathrm{MPa}$, and the depth of the maximum shear stress was $0.028 \mathrm{~mm}$. The theoretical yield strength of the upper cylinder (CuZn37) was $\leq 180 \mathrm{MPa}$, and that of the lower cylinder (pure Ag) was $\leq 54 \mathrm{MPa}$. Since the maximum shear stress was found to be $245.4 \mathrm{MPa}$, the material pairs were working the elastic-plastic range.

\subsection{Materials}

Figure 7 shows the interface configuration of the two connectors under investigation. The studied interface consists of a brass alloy substrate with $37 \mathrm{wt}$ \% zinc (CuZn37) as the upper connector.

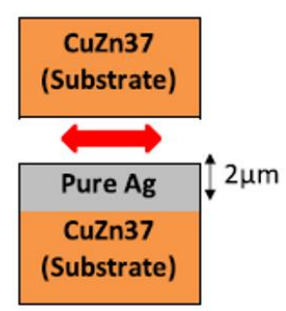

Figure 7. Interface configuration of inhomogeneous contact.

The lower connector made of the same material with pure silver layer coating with roughness approximately equal to $R_{a}=0.5 \mu \mathrm{m}$ and thickness of about $2 \mu \mathrm{m}$. Silver, being a semi-Noble material, is a good compromise between its performance and cost-effectiveness.

\section{Results and Discussion}

The following section discusses the observed effects of load and frequency in mitigating the detrimental effects of fretting.

\subsection{Effect of Load}

Contact load was observed to have a significant influence on electrical contact resistance under fretting conditions. It was observed that the detrimental effects of fretting are significantly suppressed with an increase in the contact load [21,22].

\subsubsection{Coefficient of Friction}

It is observed that for the same fretting frequency, the coefficient of friction is significantly higher at low contact loads $(1 \mathrm{~N})$ with a high degree of fluctuation, as seen in Figure 8. A standard deviation 
of 0.38 is observed at $1 \mathrm{~N}$ as compared to 0.18 at $5 \mathrm{~N}$ contact loads over the time range of 20-120 s. At a comparatively high-frequency low load condition $(10 \mathrm{~Hz}$ and $1 \mathrm{~N}$, respectively), the micromotion causes increased traverse movement due to insufficient load with high electrical contact resistance. The micromotion leads to short slip amplitudes in the perpendicular direction along the surface of the contacting connector $[18,23]$. Hence, at lower loads, an increase in friction, averaging 0.9 with a high degree of fluctuation, is observed.

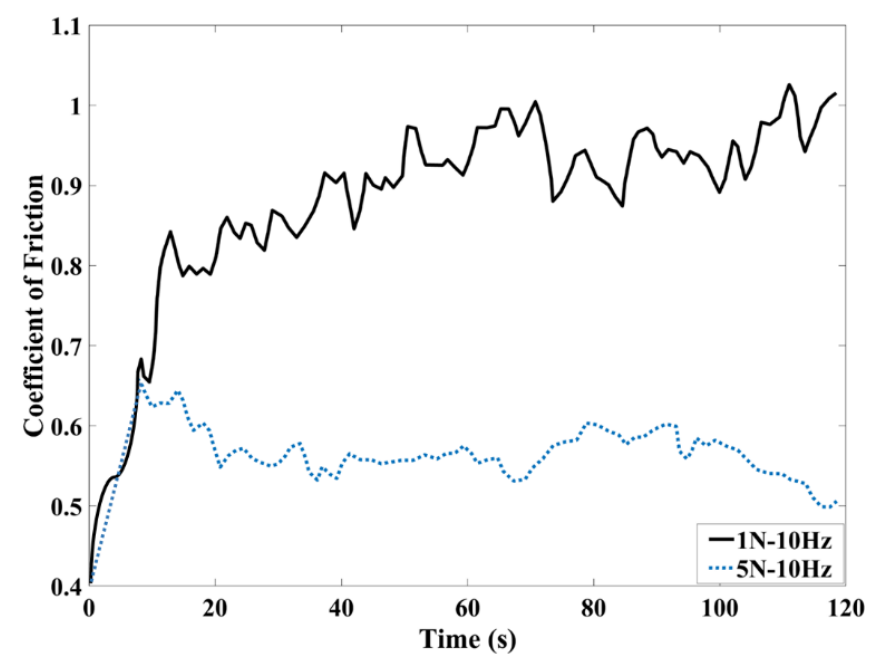

Figure 8. Effect of load on the coefficient of friction.

Though increasing the load to $5 \mathrm{~N}$ is seen to reduce the degree of fluctuations, the same condition decreases the friction by $38 \%$ to an average of 0.56 and reduces the electrical contact resistance considerably. This indicates that the increase in load is still not sufficient to suppress the fretting wear effect. This may be due to the high degree of wear particles generated due to an accumulation of plastic strain and frequent interface failure, which results in the plowing of the silver coating and accelerated damage to the contacting surfaces. Further, investigations show that there should be an optimum load which has the least amount of slip with corresponding friction coefficient (which need not be the minimum) that will lead to a high connector life span with the least ECR and coating wear [24,25].

\subsubsection{Wear}

The results observed with respect to coefficient of friction support the wear results as seen in Figure 9. The high degree of fluctuations in friction and micromotion seen at low contact load $(1 \mathrm{~N})$ cause a steady increase in the wear rate. At this load, when contact is made, the surface asperities of the brass connector penetrates the natural oxide film of the Ag-coated connector and establishes a temporary conducting path. When the micromotion occurs, there is a displacement of the contact interface during fretting; the maximum range of the fretting displacement during the tests was found to be $\pm 0.028 \mathrm{~mm}$. During these micro displacements, the interfaces and metallic bridges shear repeatedly, leading to the formation of wear debris. Some of these wear debris also oxidize to form a silver oxide with the majority of the debris remaining as metallic particles due to the burnishing effect. During this initial period, as observed in the plot below, a relatively low wear rate is found for both load conditions with good electrical conductivity [2]. After several cycles of exposure to this fatigue oxidation process, the contact zone starts to accumulate thick insulating layers of oxides and wear debris. This causes a reduction in metallic contact and leads to a sharp increase in the contact resistance. This is what leads to an increase in the wear rate seen in the latter half of the plots, which is accompanied by an increase in contact resistance.

It is observed that at high loads and high-frequency conditions, the above fretting wear phenomenon is less predominant due to the stronger embedding of the asperities of the contacting surfaces under high pressure. Research indicates that higher loads can also have a higher degree of wear [26], but the sharp increase in wear rate seen for the $5 \mathrm{~N}-10 \mathrm{~Hz}$ boundary condition indicates that they only delay 
the onset of fretting damage. It is speculated that at an optimum load in combination with a certain range of fretting frequency, this will be able to minimize the effect of adhesive bonds (micro-welds) formed during this fretting wear process and increase the working cycle of the connecting pair $[2,23]$.

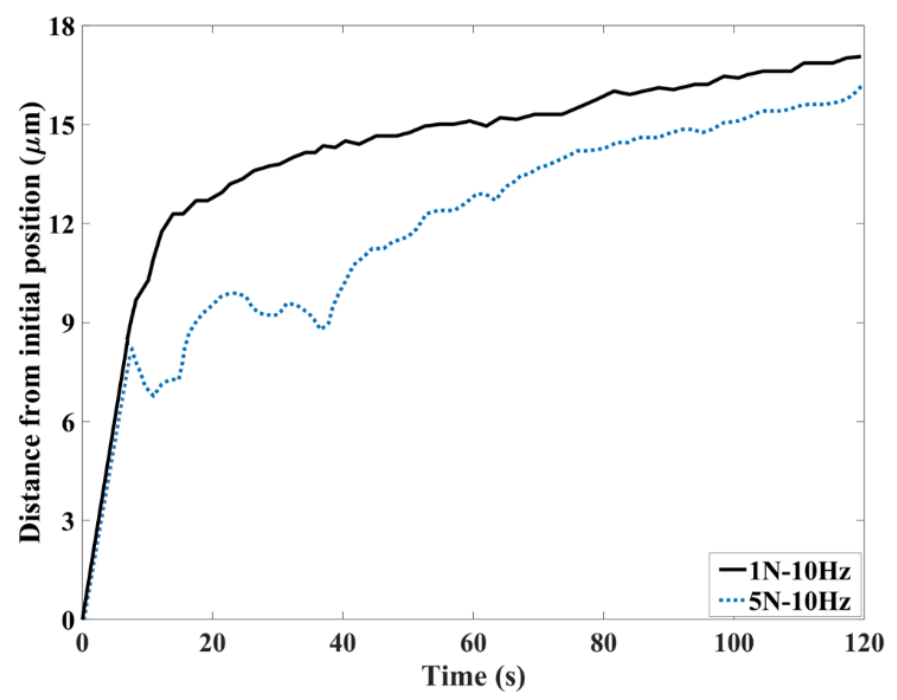

Figure 9. Effect of load on wear.

\subsection{Effect of Frequency}

Fretting is a rate dependent phenomenon, and the contact resistance is affected by the frequency of oscillations. The observed effect of frequency can be explained in terms of the oxidation factor of fretting for the connecting pair in consideration.

\subsubsection{Coefficient of Friction}

The results shown in Figure 10 are recorded at the same loading condition with varying fretting frequencies. To distinctly observe the effect fretting frequency, a sliding period of $12 \mathrm{~s}$ was considered. It indicates that at a lower frequency $(1 \mathrm{~Hz})$, there is a very high degree of fluctuation in friction. This is because oxidation is a time-dependent process wherein at lower fretting frequencies, the contact zone will be exposed to oxidation of silver coated conductor for a longer time when compared to higher fretting frequency. This results in the closure of many conducting spots in the contact zone due to oxidation, which ultimately leads to an increase in contact resistance $[1,15]$.

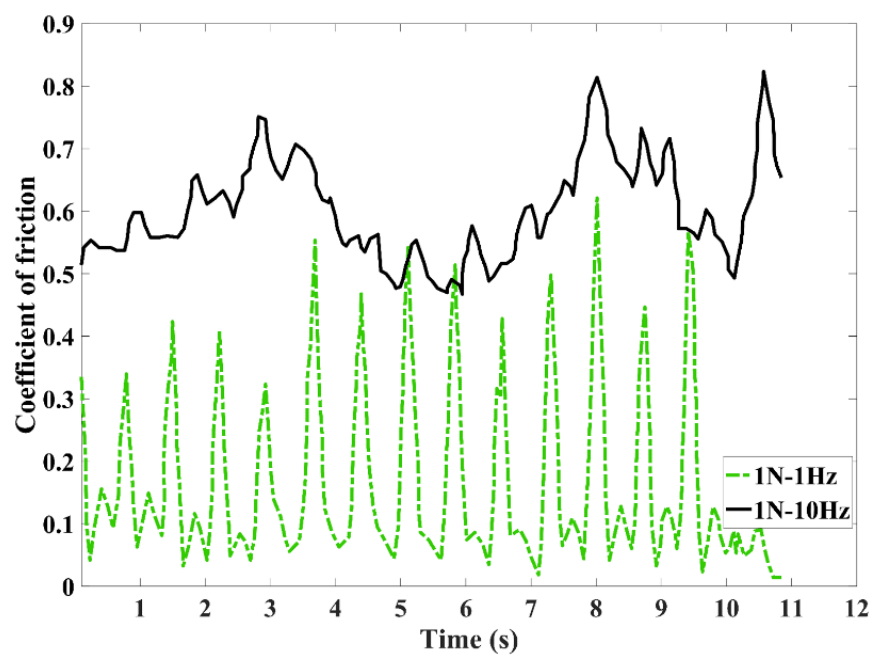

Figure 10. Effect of frequency on the coefficient of friction. 


\subsubsection{Wear}

Figure 11 shows the effect of different fretting frequency on wear. It is observed that for the same load, the wear is very minimal at low frequency $(1 \mathrm{~Hz})$ due to the low degree of oscillations. Though there is a low degree of oscillations observed with minimal wear, it shows a high degree of contact resistance at such low frequency and low contact load conditions, as discussed in the earlier section.

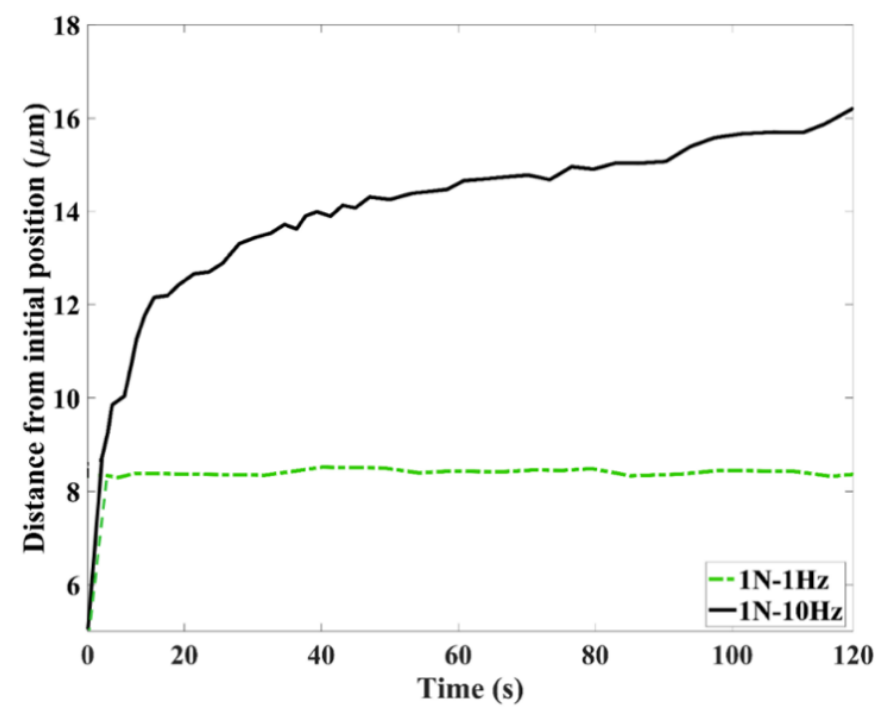

Figure 11. Effect of frequency on wear.

\subsubsection{Surface Analysis}

Figure 12a shows the surface analysis where silver oxide and brass wear debris accumulated at the end of a fretting cycle. These wear debris were formed during the fretting at $5 \mathrm{~N}$ load and $10 \mathrm{~Hz}$ fretting frequency. The silver oxide in the wear debris significantly affects the kinetics of fretting damage, which is the main reason behind the increase in the coefficient of friction. These wear debris act as an abrasive, which further increase the surface damage at the contact interface, accelerating the wear of the silver coated connector. Since the pair of connectors is such that a soft metal (brass) is producing a hard oxide (silver oxide), this results in severe wear as seen through the wear track in Figure 12b. The depth of the wear track is found to be $8.11 \mu \mathrm{m}$, which indicates the severe wear that the combination of silver oxide and brass substrate wear debris have caused on the connector. Figure 12c shows various roughness amplitude parameters that are observed along the wear track. The Kurtosis value of 7.835 , which is $>>3$, indicates that there is a very sharp dent along the area of contact between the connectors that has led to the increase in electrical contact resistance. Figure 12 also illustrates the slip regime condition during testing. There are no cracks present on the wear track that suggest the gross slip fretting regime. Presence of any cracks would have resulted in the partial slip fretting regime $[27,28]$. 
a)

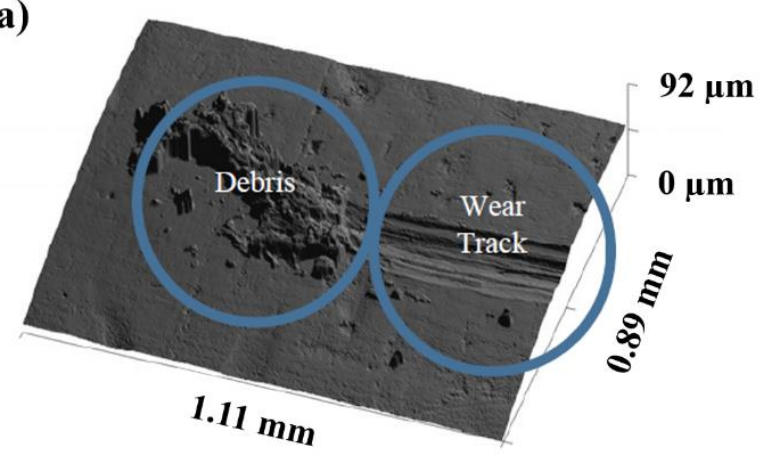

b)

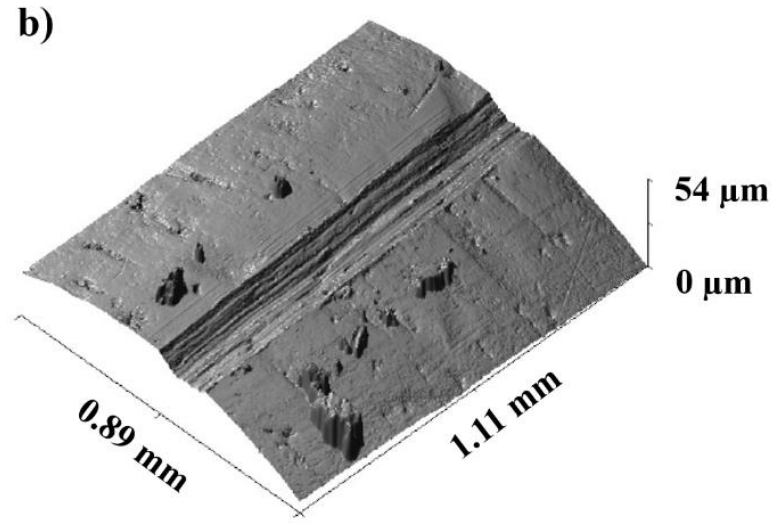

c)

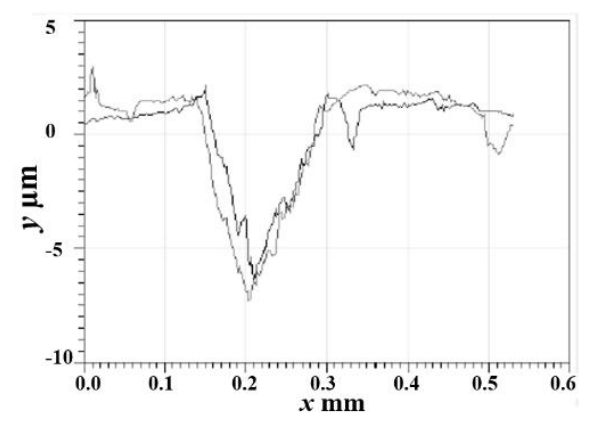

$R_{a} \quad$ Avg. roughness

$0.16 \mu \mathrm{m}$

$R_{q} \quad$ Root mean square roughness

$0.25 \mu \mathrm{m}$

$R_{t} \quad$ Max. height of the roughness

$2.17 \mu \mathrm{m}$

$R_{v} \quad$ Max. roughness valley depth

$0.92 \mu \mathrm{m}$

$R_{p} \quad$ Max. roughness peak height

$1.25 \mu \mathrm{m}$

$R_{z} \quad$ Avg. max. height of the profile

$1.37 \mu \mathrm{m}$

$R_{s k} \quad$ Skewness

0.423

$R_{k u} \quad$ Kurtosis

Figure 12. Surface analysis at $5 \mathrm{~N}$ load and $10 \mathrm{~Hz}$ fretting frequency. (a) Oxide and metallic debris accumulated at the end of the wear track of the contact interface. (b) The 3D surface profile of the wear track on the Ag-coated connector. (c) An illustration of the 2D wear track profile, and the roughness amplitude parameters averaged from five random locations on the wear track.

\section{Conclusions}

The study presents an insight into the detrimental effects of fretting wear and its influence on the performance of a brass connector in contact with an Ag-coated connector. It was observed that micro-motion at the contact interface is significantly influenced by the contact load and fretting frequency under consideration, the combination of which leads to varying degrees of fretting wear. It was shown that at a comparatively high-frequency low load condition ( $10 \mathrm{~Hz}$ and $1 \mathrm{~N})$, the micromotion at the interface caused an increase in traverse movement due to insufficient load which led to high electrical contact resistance. The micro-motion was also seen to create short slip amplitudes in the perpendicular direction along the surface of the contacting connector. It was also shown that at high loads and high-frequency conditions, the above fretting wear phenomenon was less predominant due to the stronger embedding of the asperities of the contacting surfaces under high pressure. The study indicates that there is an optimum load for a specific range of fretting frequency through which the fretting wear can be minimized. Further studies in this regard are suggested wherein a model would be able to predict the optimum load for a specific range of fretting frequencies.

Author Contributions: Conceptualization: A.S., A.K.K., P.L.M.; Methodology: P.L.M., V.K.; Formal Analysis: A.S., A.K.K.; Investigation: A.S., A.K.K.; Resources: P.L.M., V.K.; Original Draft Preparation: A.S.; Writing一Review \& Editing, A.S., A.K.K., P.L.M.; Supervision: P.L.M.; Project Administration: P.L.M.

Funding: This research received no external funding. We thank Rtec-instruments and Department of Mechanical Engineering at University of Nevada-Reno, Nevada, USA for facilitating this research.

Conflicts of Interest: The authors declare no conflict of interest. 


\section{References}

1. Pompanon, F.; Laporte, J.; Fouvry, S.; Alquier, O. Normal force and displacement amplitude influences on silver-plated electrical contacts subjected to fretting wear: A basic friction energy-contact compliance formulation. Wear 2019, 426, 652-661. [CrossRef]

2. Larsson, E.; Andersson, A.M.; Kassman Rudolphi, Å. Grease lubricated fretting of silver coated copper electrical contacts. Wear 2017, 376, 634-642. [CrossRef]

3. Laporte, J.; Perrinet, O.; Fouvry, S. Prediction of the electrical contact resistance endurance of silver-plated coatings subject to fretting wear, using a friction energy density approach. Wear 2015, 330, 170-181. [CrossRef]

4. Bock, E.M.; Whitley, J.H. Fretting corrosion in electric contacts. In Proceedings of the Twentieth Annual Holm Seminar on Electrical Contacts, Chicago, IL, USA, 29-31 October 1974; pp. 128-138.

5. Mason, W.P.; White, S.D. New Techniques for Measuring Forces and Wear in Telephone Switching Apparatus. Bell Syst. Tech. J. 1952, 31, 469-503. [CrossRef]

6. Liu, X.; Cai, Z.; Liu, S.; Wu, S.; Zhu, M. Influence of Wear Test Parameters on the Electrical Contact Performance of Brass Alloy/Copper Contactors Under Fretting Wear. J. Mater. Eng. Perform. 2019, 28, 817-827. [CrossRef]

7. Laporte, J.; Fouvry, S.; Alquier, O. Prediction of electrical contact resistance failure of Ag/Ag plated contact subjected to complex fretting-reciprocating sliding. Wear 2017, 376, 656-669. [CrossRef]

8. Saka, N.; Liou, M.J.; Suh, N.P. The role of tribology in electrical contact phenomena. Wear 1984, 100, 77-105. [CrossRef]

9. Braunovic, M. Surface Analysis of Fretting Damage in Electrical Connectors. In New Materials Approaches to Tribology: Theory and Applications (1988); Materials Research Society: Pittsburgh, PA, USA, 1988; Volume 140, pp. 405-412.

10. Kogut, L.; Etsion, I. Electrical Conductivity and Friction Force Estimation in Compliant Electrical Connectors. Tribol. Trans. 2000, 43, 816-822. [CrossRef]

11. Perrinet, O.; Fouvry, S.; Alquier, O. Application of the Friction Energy Density Approach to Predict Electrical Contact Endurance in a Silver-Plated Coating Subjected to Fretting Wear. In Proceedings of the 2013 IEEE 59th Holm Conference on Electrical Contacts (Holm 2013), Newport, RI, USA, 22-25 September 2013; pp. 1-10.

12. Ren, W.; Wang, P.; Song, J.; Zhai, G. Effects of current load on wear and fretting corrosion of gold-plated electrical contacts. Tribol. Int. 2014, 70, 75-82. [CrossRef]

13. Antler, M.; Drozdowicz, M.H. Fretting corrosion of gold-plated connector contacts. Wear 1981, 74, $27-50$. [CrossRef]

14. Belakhdar, R.; Noël, S.; Alamarguy, D.; Schneegans, O.; Boccaletti, G. Effect of fluorinated lubricants on the friction modes of tin electrical contacts submitted to fretting. Eur. Phys. J.-Appl. Phys. 2010, 49, 22903. [CrossRef]

15. Park, Y.W.; Narayanan, T.S.N.S.; Lee, K.Y. Fretting corrosion of tin-plated contacts. Tribol. Int. 2008, 41, 616-628. [CrossRef]

16. Heitz, E. Fretting Corrosion. Von, R. B. Waterhouse. 253 S. 306 Abb., 13 Tab. 1972, Pergamon Press, Oxford, New York, Toronto, Sydney, Braunschweig. Geb. Mater. Corros. 1975, 26, 172-173.

17. Hurricks, P.L. The mechanism of fretting-A review. Wear 1970, 15, 389-409. [CrossRef]

18. Braunovic, M. Fretting in Electrical/Electronic Connections: A Review. IEICE Trans. Electron. 2009, 92,982-991. [CrossRef]

19. Myshkin, N.K. Tribological problems in electrical contacts. Tribol. Int. 1991, 24, 45-49. [CrossRef]

20. Puttock, M.J.; Thwaite, E.G. Elastic compression of spheres and cylinders at point and line contact. In Elastic Compression of Spheres and Cylinders at Point and Line Contact; Puttock, M.J., Thwaite, E.G., Eds.; Commonwealth Scientific and Industrial Research Organization: Melbourne, Australia, 1969; p. 11.

21. Braunovic, M. Effect of contact load on the contact resistance behavior of different conductor and contact materials under fretting conditions. In Proceedings of the International Conference on Electrical Contact Phenomena, Nuremberg, Germany, 14-17 September 1998; Schröder, K.-H., Ed.; VDE-Verlag: Nuremberg, Germany, 1998; pp. 283-287.

22. Lee, A.; Mamrick, M. Fretting corrosion of Tin-plated copper alloy. IEEE Trans. Compon. Hybrids Manuf. Technol. 1987, 10, 63-67. [CrossRef] 
23. Kassman, A.; Jacobson, S. Surface damage, adhesion and contact resistance of silver plated copper contacts subjected to fretting motion. Wear 1993, 165, 227-230. [CrossRef]

24. Wang, Q.; Wang, Y.; Wang, H.; Fan, N.; Yan, F. Experimental investigation on tribological behavior of several polymer materials under reciprocating sliding and fretting wear conditions. Tribol. Int. 2016, 104, 73-82. [CrossRef]

25. Trinh, K.E.; Ramos-Moore, E.; Green, I.; Pauly, C.; Zamanzade, M.; Mucklich, F. Topographical and Microstructural Effects of Laser Surface Texturing on Tin-Coated Copper Electrical Connectors under Load Cycling. IEEE Trans. Compon. Packag. Manuf. Technol. 2017, 7, 582-590. [CrossRef]

26. Menezes, P.L.; Ingole, S.P.; Nosonovsky, M.; Kailas, S.V.; Lovell, M.R. Tribology for Scientists and Engineers; Springer: Berlin/Heidelberg, Germany, 2013; pp. 9-28.

27. Gallego, L.; Nélias, D. Modeling of Fretting Wear under Gross Slip and Partial Slip Conditions. J. Tribol. 2007, 129, 528-535. [CrossRef]

28. Vincent, L.; Berthier, Y.; Godet, M. Testing Methods in Fretting Fatigue: A Critical Appraisal. In Standardization of Fretting Fatigue Test Methods and Equipment; Attia, M.H., Waterhouse, R.B., Eds.; ASTM International: West Conshohocken, PA, USA, 1992; pp. 33-48.

(C) 2019 by the authors. Licensee MDPI, Basel, Switzerland. This article is an open access article distributed under the terms and conditions of the Creative Commons Attribution (CC BY) license (http://creativecommons.org/licenses/by/4.0/). 